\title{
Auf der Suche nach Wahrheit und Wahrhaftigkeit
}

\author{
Reflexionen zum Artikel «Töten aus 〈Gnade〉?» in dieser Ausgabe
}

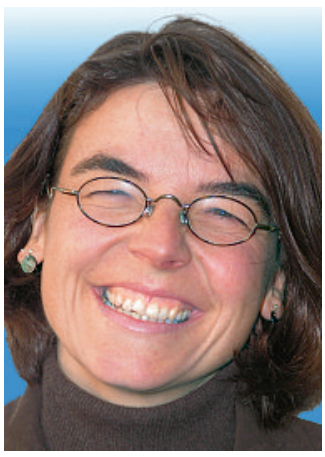

Christina Aus der Au

Was ist Wahrheit? So fragt Pilatus den ihm vorgeführten Jesus, und seither haben nach ihm viele ihre Wahrheiten präsentiert. Und ebenso viele haben deren Wahrheiten ihrerseits wiederum problematisiert.

Dr. med. Roland Moser bezeichnet seinen Artikel «Töten aus «Gnade??» auf Seite 822 als einen «fragmentarischen Versuch, der Wahrheit näherzukommen». Darin kritisiert er die säkulare Verteidigung von aktiver Sterbehilfe aus der Sicht eines christlichen Menschenbildes, welches das Akzeptieren der menschlichen Endlichkeit mit der Hoffnung auf die Ewigkeit verbindet und nur das barmherzige, begleitende Ausharren beim Leidenden zulässt.

Bei der Sterbehilfe Zuflucht zu nehmen, heisst Moser zufolge, der Tatsache auszuweichen, dass Leben mit Erleben und Erleiden zusammenhängt, dass nicht alles mess- und machbar ist, und dass letztlich allein bei Gott Zuflucht gefunden werden kann. Der christliche Arzt weiss deswegen um die Notwendigkeit seiner mitleidenden und seelsorgerlichen Präsenz jenseits von Heilbarkeit - aber diesseits aktiver Sterbehilfe.

\section{Können wir denn beurteilen, wer näher an der «Wahrheit» ist - der christliche oder der säkulare Arzt?}

* PD Dr. theol. Christina Aus der Au ist an der Abteilung Systematische Theologie/ Dogmatik der Universität Basel tätig und Mitglied der Redaktion Ethik der Schweizerischen Ärztezeitung.
Aber weiss das auch der säkulare Arzt, der keine Zuflucht bei Gott kennt? Weiss das auch die christliche Ärztin, deren Verständnis von Barmherzigkeit gerade beinhaltet, dass unerträgliches Leiden beendet werden darf? Müssten sie es wissen? Müssten sie es erkennen, wenn sie der Wahrheit näher stünden? Oder haben diese eine andere Wahrheit?

Was ist Wahrheit? Können wir denn beurteilen, wer näher dran ist (wenn es denn die eine Wahrheit geben sollte), der christliche oder der säkulare Arzt? Der christliche Arzt aus Barmherzigkeit gegen Sterbehilfe, die christliche Ärztin aus Barmherzigkeit dafür?

Kann es in praktischen Fragen um Leben und Tod überhaupt um eine Wahrheit gehen, die wir als Menschen doch höchstens nur vorläufig erkennen können? Oder geht es in diesem Artikel nicht vielmehr um das narrative Entfalten eines bestimmten christlichen Menschen- und Gottesbildes, dem geneigten Ohr veranschaulicht und plausibilisiert durch Geschichten, Beispiele und Zitate, aber kaum geeignet als argumentativer Beitrag zu einer Diskussion mit rationalem An- spruch? Und deswegen zu Recht qualifiziert als wohl moralischer Standpunkt, nicht aber als ethische Reflexion?

Auf der anderen Seite: Setzen nicht auch die argumentativen Diskussionsbeiträge für oder gegen die Sterbehilfe ein bestimmtes Menschenbild voraus? Und bestehen nicht auch sie im Veranschaulichen und Plausibilisieren von persönlichen Überzeugungen, oft auch mithilfe von Fallbeispielen und Geschichten?

Damit soll nicht der Unterschied zwischen Moral (oder gar Religion) und Ethik zum Verschwinden gebracht werden. Die eigenen moralischen Überzeugungen müssen vor dem Forum der öffentlichen, d.h. im Prinzip von allen nachvollziehbaren, Vernunft gerechtfertigt werden können. Aber ihr Feuer, ihre Motivationskraft, erhalten sie nicht aus der Vernunft, sondern aus ihrer Funktion in Geschichten, letztlich aus ihrer Funktion in der jeweils eigenen Lebensgeschichte.

Es ist nicht Wahrheit, sondern Wahrhaftigkeit, die wir zu Recht von ethischen Reflexionen und den darunterliegenden moralischen Motivationen verlangen. Der Verweis auf das Annehmen der eigenen Endlichkeit (und derjenigen der anderen) und die Hoffnung auf eine Ewigkeit kann auch Intuitionen und Anliegen von Menschen aufnehmen, die das vorausgesetzte Menschenbild oder das Vertrauen in die von Moser zitierten Autoritäten nicht teilen. Die Kritik am Machbarkeitswahn, der die Machbarkeit des Sterbens beinhaltet, können auch Menschen teilen, die ihre Verantwortung in erster Linie den Menschen und nicht Gott gegenüber sehen. Und zur Vorsicht mahnen vor der «Sterbehilfe aus Gnade» wollen vielleicht auch Menschen, die aktive Sterbehilfe als persönliche Gewissensentscheidung nicht ausschliessen wollen.

Der amerikanische Philosoph Ronald Dworkin hält den Versuch, einen anderen Menschen zu zwingen, auf eine Art und Weise zu sterben, die für andere, aber nicht für ihn selber richtig ist, für eine abscheuliche Form von Tyrannei. Wenn wir Gesetze machen müssen, schreiben wir damit anderen vor, wie sie zu leben - und in diesem Fall zu sterben - haben. Die Wahrhaftigkeit anderer ernst zu nehmen, heisst in diesem Fall, so meine ich, Gesetze über Sterbehilfe so zu formulieren, dass für möglichst viele Menschen ihre eigene Art zu leben und zu sterben möglich bleibt, ohne dass ich dabei auf meine Wahrhaftigkeit im eigenen Handeln und Reden verzichten muss.

Christina Aus der Au* 